\title{
Commitment to activities and quality of life and associated factors in patients with chronic pain
}

\begin{abstract}
Background: Chronic pain leads to functional and social disability, emotionally impacting individuals.

Objective: To describe the main impairments of activities of daily living, anxious and depressive symptoms and quality of life in patients with chronic pain.

Methods: Cross-sectional study with patients at the Chronic Pain Clinic attended between June / 2016 and March / 2019. Clinical and socio-demographic variables were collected, using the Hospital scale for Anxiety and Depression, Visual Numerical Scale for Pain, SF36 scale for Quality of Life, and data analysis using the SPSS statistical program.

Results: The mean age was $50.0 \pm 10$ years, being ( $89.6 \%)$ female. There was a predominance of people with a partner, with religion, complete high school education and unemployed. Degenerative disease was the most frequent diagnosis (68.9\%); pain intensity ranged from moderate to severe, score 6-8 (7). Most used drugs were analgesics (93.3\%) followed by antidepressants $(70.7 \%)$. Physical activity as an adjuvant treatment $(41.5 \%)$, and anesthetic blocks $(39.6 \%)$. When investigating daily activities, the work showed total limitation followed by movement; and, partially, leisure and home activity. The quality of life was well below the median, with the physical and emotional aspects being worse. Related to the subjects' activities, sleep is the most compromised; followed by partial difficulties with appetite and sexual activity. Most show self-esteem moderately satisfied with the treatment, even with anxious and depressive symptoms.
\end{abstract}

Conclusion: Pain has a very significant impact on quality of life; compromises and limits daily activities and reveals more presence of anxious and depressive symptoms in people suffering from chronic pain.

Keywords: quality of life, anxiety, depression, activities, chronic pain
Volume 10 Issue 5 - 2020

\author{
Sandro Max Castro Silva,' Carla Hilário da \\ Cunha Daltro, ${ }^{2}$ Martha Moreira Cavalcante \\ Castro, ${ }^{3}$ Camila Cavalcante Castro, ${ }^{4}$ Raphael \\ de Souza Borges, ${ }^{5}$ Marcos Almeida Matos ${ }^{6}$ \\ 'Bahiana School of Medicine and Public Health, Brazil \\ ${ }^{2}$ Department of Nutrition, Federal University of Bahia, Brazil \\ ${ }^{3}$ Department of Physiotherapy, Federal University of Bahia, Brazil \\ ${ }^{4}$ Faculty of Technology and Science, Brazil \\ ${ }^{5}$ Federal University of Bahia, Brazil \\ ${ }^{6}$ Bahiana School of Medicine and Public Health, Brazil
}

Correspondence: Sandro Max Castro Silva, Bahiana Schoo of Medicine and Public Health, Av. Prof. Magalhães Neto, 154 I - sala 3014 - Pituba, Salvador, Bahia, Brazil, +5571991946360, Email sandromax65@gmail.com

Received: July 30, 2020 | Published: September 23, 2020

\section{Introduction}

Pain is a very prevalent symptom in most diseases, and may even exist as a single condition, also becoming a specific syndrome. ${ }^{1-3}$ It is believed that approximately $80 \%$ of the world population regularly appears in health systems with complaints of some type of pain. ${ }^{4,5}$ Chronic pain, in addition to being a serious disease, has a complex psychosocial and biological basis. Data described in the 2007 United States census and also an IASP report, show that chronic pain affects around 45 million adult individuals and that when left untreated it is associated with a loss of about $\$ 61$ billion in productivity to every year. ${ }^{6}$ Chronic pain affects more than 50 million Americans and these productivity costs can reach more than 100 billion annually. ${ }^{7}$

In Brazil, pain is considered a public health problem and it is estimated that about $29.3 \%$ to $73.3 \%$ of the population has this clinical condition. However, the true prevalence of chronic pain in the Brazilian population can hardly be accurately estimated; the vast majority of studies are regional and very heterogeneous. ${ }^{8}$

Chronic pain, unlike acute pain, is not just a symptom, but a pathology resulting from a dysfunction of the somatosensory system. This condition persists even after the removal of the painful stimulus and it is often difficult to define precisely in the clinic, the etiological factor because it is a complex pathology. ${ }^{9}$ The presence of chronic painful conditions causes important multifactorial changes and, especially when associated with depressive symptoms, is able to greatly interfere with the individual's quality of life. ${ }^{10}$
Studies reporting the prevalence of psychological disorders in association with chronic pain have been widely published. ${ }^{4,5,11}$ Among psychiatric disorders, major depression was the most studied and is a condition present in most patients with chronic pain. ${ }^{12}$ It is estimated that depressive disorders reach percentages between $30 \%$ and $87 \%$ of cases, varying from $8 \%$ to $50 \%$ when major depression is diagnosed. Anxiety is also present in about $56 \%$ of subjects with chronic pain, and in only about $10 \%$ of them, the onset occurred after the painful event. ${ }^{13}$

It is known that chronic pain affects the personal and professional lives of patients, becoming a factor that worsens the quality of life. There is physical disability, interference with work, leisure with the family, taking the individual out of social life and causing psychological distress. The severe interference with regular activities associated with depression makes these relationships complex and difficult to understand. ${ }^{14}$

This study aims to describe the main impairments in activities of daily living, anxious and depressive symptoms and the quality of life of patients with chronic pain.

\section{Materials and methods}

A cross-sectional study was carried out with patients with chronic pain and their comorbidities followed at a referral clinic in the state of Bahia. Sample of subjects seen at the Pain Ambulatory at UFBA Professor Edgard Santos Hospital Complex (HUPES) in Salvador / 
Bahia. Data collection ranged from June 2016 to March 2019. Patients of both genders and age group between 18 and 80 years were included and subjects with difficulty in understanding the objectives of the present study were excluded; individuals who did not complete the protocol, and patients with Oncological Pain.

The following instruments were used: Questionnaire of sociodemographic and clinical data composed of questions referring to the social and demographic characterization of the subjects, as well as information regarding pain and its repercussions; Visual Numeric Scale $(\mathrm{EVN})^{15}$ consisting of a line, graded from 0 to 10 , where zero represents absence of pain and ten represents the worst pain imaginable. The values obtained were categorized as follows: 0 $=$ no pain; 1,2 and $3=$ mild pain; 4, 5 and $6=$ moderate pain; 7, 8 and $9=$ severe or severe pain; and $10=$ unbearable pain; Hospital Anxiety and Depression Scale (HAD), which has 14 questions, 07 for anxiety and 07 for depression, with cutoff point 08 for anxiety and 09 for depression; ${ }^{16}$ SF-36 Quality of Life Scale (Medical Outcomes Study 36 - Item-ShortForm Health Survey) generic instrument that assesses the following dimensions: Functional Capacity (ability to take care of oneself and perform activities of daily living); Physical Aspects (impact of physical health to perform your activities); Pain (level of pain for the performance of your daily activities); General Health Status (how the individual perceives his health); Vitality (physical vigor); Social Aspects (impact of physical conditions on your social life); Emotional Aspects (the emotional interfering in your daily activities) and Mental Health (interference of the mood state in your life). To analyze the eight dimensions of the scale, scores from 0 (most compromised) to 100 (no impairment) were used. ${ }^{17}$

Individuals were invited to participate in the research by signing the free and informed consent term, obeying the Regulatory Guidelines and Norms for Research Involving Humans, according to Resolution No. 466/12 of December 12, 2012, of the National Health Council - Ministry of Health (Anvisa, 2004). The project was approved by the Research Ethics Committee, with CAAE number 49909615.8.0000.0049 and Opinion number 1.446.343.

For the analysis and tabulation of the data, the SPSS Statistical Program version 17.0 was used. Quantitative variables were expressed as means and standard deviations, and categorical variables were expressed as simple, absolute and relative frequencies. The variables "Visual Numerical Scale" and "Quality of Life Scale - SF-36" were considered ordinal variables (scores) and presented as the median and interquartile range. Values of $p<0.05$ were considered statistically significant.

\section{Results}

The average age of the 164 subjects evaluated was 50 years old, of which $89.6 \%$ were female. It was observed that there was a higher prevalence of patients with a partner, who have religion, high school education and who are unemployed (63.4\%) (Table 1).

Regarding the clinical diagnosis, the most prevalent found in this sample were those related to degenerative diseases $(68.9 \%)$ and as for the intensity, the pain ranged from moderate to severe. When asked about the use of medications, analgesics (93.3\%) followed by antidepressants $(70.7 \%)$ were the most used. Regarding the other treatments performed by this sample, physical activity (41.5); anesthetic blocks (39.6) followed by physiotherapy (34.8) and acupuncture (34.8) were the most commonly found and most individuals assessed improvement in their treatment (Table 2).
Table I Sociodemographic characteristics of patients with chronic pain at the Pain Clinic of C-HUPES / UFBA, from June 2016 to March 2019, SalvadorBahia

\begin{tabular}{ll}
\hline Characteristics & Results \\
\hline Age (full years) & $50(10) *$ \\
Female & $147(89,6 \%)$ \\
Marital Status & $96(58,5)$ \\
With partner & $68(41,5)$ \\
Without partner & $155(94,0)$ \\
With religion & $2(1,2)$ \\
Education & $64(39,0)$ \\
$\quad$ No schooling & $80(48,8)$ \\
Complete / incomplete elementary & $18(1 \mathrm{I}, 0)$ \\
school & $17(10,4)$ \\
Complete / incomplete high school & \\
Complete / incomplete higher education
\end{tabular}

* values expressed as mean and standard deviation

Table 2 Diagnosis and treatments used to control pain in patients treated at the Pain Clinic of C-HUPES / UFBA, from June 2016 to March 2019, SalvadorBahia

\begin{tabular}{ll}
\hline Variables & Results \\
\hline Clinical Diagnosis & $113(68,9)$ \\
Degenerative disease & $89(54,3)$ \\
Rheumatic disease & $47(28,7)$ \\
Work-related disease & \\
Pain Intensity (ENV) & $7(6-8)^{*}$ \\
Painless & $2(1,2)$ \\
Light & $4(2,4)$ \\
Moderate & $54(33)$ \\
Intense & $88(54)$ \\
Unbearable & $16(9,8)$ \\
Class of Medicines in use & $153(93,3)$ \\
Pain relievers & $\mathrm{II}(70,7)$ \\
Antidepressants & $46(28,8)$ \\
Anticonvulsants & $39(23,8)$ \\
Benzodiazepines & $22(13,4)$ \\
Anti-inflammatories & $18(\mathrm{II})$ \\
Others & \\
Other treatments & \\
\hline Physical activity/ Pilates & \\
\hline
\end{tabular}


Table continue

\begin{tabular}{ll}
\hline Variables & Results \\
\hline Anesthetic blocks & $65(39,6)$ \\
Physiotherapy & $57(34,8)$ \\
Acupuncture & $57(34,8)$ \\
Chiropractic & $8(4,9)$ \\
Treatament Evaluation & \\
Improved & $94(57)$ \\
Worsened & $21(13)$ \\
Same thing & $49(30)$
\end{tabular}

* Data in median and interquartile range

Regarding the daily limitations related to their activities, partial difficulties were found in the items Movement, Leisure and Home Activity and a higher frequency with total limitation in the item related to Work (Table 3). When assessing the commitments related to daily activities, partial difficulty was found in relation to Appetite and Sexual Activity. There was no commitment to Personal Hygiene and the items related to Sleep were very significant with the majority (95\%) presenting some or total difficulty. The most frequent selfesteem and personal satisfaction were moderate. Anxious and depressive symptoms appear in most subjects assessed (Table 4).

Table 3 Daily limitations of patients with chronic pain treated at the Pain Clinic of C-HUPES / UFBA, 2016 to 2019, Salvador-Bahia

\begin{tabular}{ll}
\hline Limitations & $\mathbf{n}(\%)$ \\
\hline Movement & $77(47)$ \\
Total & $83(5 \mathrm{I})$ \\
Partial & $4(2,4)$ \\
Without limitations & \\
Job & $121(74)$ \\
Total & $36(22)$ \\
Partial & $7(4,3)$ \\
Without limitations & \\
Recreation & $66(40)$ \\
Total & $86(53)$ \\
Partial & $12(7,3)$ \\
Without limitations & \\
Home Activity & $61(37)$ \\
Total & $93(57)$ \\
Partial & $10(6,1)$ \\
Without limitations &
\end{tabular}

Table 4 Commitment to the activities of patients treated at the Pain Clinic of C-HUPES / UFBA, 2016 to 2019, Salvador-Bahia

\begin{tabular}{ll}
\hline Commitment & $\mathbf{n}(\%)$ \\
\hline Sleep & \\
Total & $77(47)$ \\
Partial & $79(48)$ \\
\hline
\end{tabular}

Table continue

\begin{tabular}{ll}
\hline Commitment & $\mathbf{n}(\%)$ \\
\hline Sleep & \\
No compromise & $8(5)$ \\
Appetite & $38(23)$ \\
Total & $74(45)$ \\
Partial & $52(32)$ \\
No compromise & \\
Sexual Activity & $60(37)$ \\
Total & $73(45)$ \\
Partial & $31(19)$ \\
No compromise & \\
Personal hygiene & $8(5)$ \\
Total & $58(35)$ \\
Partial & $98(60)$ \\
No compromise & \\
Self esteem & $28(17)$ \\
Terrible & $13(8)$ \\
Bad & $88(53)$ \\
Moderate & $32(20)$ \\
Good & $3(2)$ \\
Great & $97(59)$ \\
Norsonal Satisfaction & $9(5,5)$ \\
Not very satisfied & $32(20)$ \\
Moderately satisfied & \\
Well satisfied & \\
Very satisfied & $(46)$ \\
\hline
\end{tabular}

The Table 5 reveals the results of the evaluation of quality of life using SF-36 scale, showing that the worst domains are the physical and emotional aspects.

Table 5 Quality of Life Assessment of 164 patients with chronic pain at the Pain Clinic of C-HUPES / UFBA, from June 2016 to March 2019, Salvador-Bahia

\begin{tabular}{ll}
\hline SF36 Domains & Results* \\
\hline Functional Capacity & $25(15-40)$ \\
Physical Aspects & $0(0-25)$ \\
Pain & $22(12-35)$ \\
General Health Status & $35(25-50)$ \\
Vitality & $30(15-45)$ \\
Social Aspects & $38(25-52)$ \\
Emotional Aspects & $12(0-67)$ \\
Mental Health & $40(27-63)$ \\
\hline
\end{tabular}

* Data expressed as Median and Interquartile range 


\section{Discussion}

The results obtained in this study show that the majority of patients with chronic pain are female, as observed in other studies. ${ }^{18,19}$ The justification for this fact is that women have lower threshold and tolerance to pain, ${ }^{20}$ in addition to anatomical features such as shorter stature, lower muscle and bone mass index, more fragile joints and greater hormonal variations in relation to men, which contribute to greater mechanical overload and, consequently, makes the occurrence of pain more frequent. ${ }^{21}$

The intensity of moderate and severe pain found in this study corroborates with the literature demonstrating that in reference centers, high pain intensity scores are observed, with continuous duration and with comorbidities that directly affect quality of life, which generates significant socioeconomic impact and, consequently, increased concern of public health managers in these cases. ${ }^{22}$

In this study, most subjects had some religion, as found in the study by Pinheiro et al., ${ }^{23}$ where he detected that most patients with complaints of severe pain have some religion, especially Catholic and evangelical. There is research that indicates that religiosity helps in the way of dealing with pain, as it increases its threshold, and its practice activates the prefrontal cerebral cortex, in addition to raising rates of neurotransmitters such as serotonin, GABA and dopamine, all directly involved with the pathophysiology of pain. ${ }^{24}$

This sample identifies that most of the subjects were unemployed. This stems from the fact that the sample was obtained at a reference center for the treatment of pain and, as the withdrawal from work activities is often part of the illness process, unemployment is a late consequence. Regarding the clinical diagnosis, the highest prevalence found in this sample was related to degenerative diseases; among these, low back pain (low back pain) is the most frequent and, when associated with psychosocial conditions and the work environment, it becomes one of the main causes of absenteeism becoming a substantial factor of impact on economic and social costs..$^{25,26}$

When asked about the use of medications, analgesics were the most used by patients, followed by antidepressants. Most painful conditions involve several different aspects and the use of analgesics as a single agent may not be adequate to relieve chronic pain. In some situations, the association of analgesics with two or more medications can result in synergistic effects and provide greater efficacy in pain relief, with antidepressants being an important part of the therapeutic strategy. ${ }^{26,27}$

Regarding the other treatments performed by this sample, more frequent use of physical activity was found; treatment with anesthetic blocks, followed in a similar way, the use of physiotherapy and acupuncture. Physical activity and physiotherapy are key components in rehabilitation from the biopsychosocial point of view in individuals with chronic pain. Exercise contributes to reducing pain in addition to improving physical functions. When this activity is at a high level, it results in a benefit in quality of life and emotional well-being. ${ }^{28}$

Assessing the treatment response as best can be related to how much the individual has expectations about what he has been doing. Scholars corroborate this finding when they point out that patients with chronic pain, in general, undergo numerous pharmacological interventions or not for pain control, need to maintain a good therapeutic alliance and have their own beliefs about their treatment. This causes expectations to vary over the years of illness, influencing responses. As with chronic pain, the goal is to increase the quality of life and alleviate suffering; contrary to the logic of pain cure, the patient's expectations that may change and differ from the expectations created by the health team throughout the process. ${ }^{29}$

The findings of our study showed that patients with chronic pain when evaluated by the SF-36 demonstrated a quality of life well below, when compared with the average of the Brazilian population, in all domains; the ones with the worst scores were physical and emotional aspects. ${ }^{30}$

The work-related limitations for the individual suffering from chronic pain are very severe. This is related to low productivity and inability to perform their activities, which determines a loss in their general well-being and ends up compromising the dynamics of moving around to carry out their daily activities, culminating in changes in mood, leisure, sleep and quality of life, in addition to interfering negatively in interpersonal relationships. ${ }^{31}$

Often, individuals report a negative self-perception when interacting socially, with frustration and shame when needing to perform their daily activities. There are even reports of little understanding of their illness not only from work colleagues, but from family members, partners and children. This causes significant suffering and loss of work identity not only from a social point of view, but also in affective relationships, as it compromises sexual activity and can interfere by lowering the mood present in anxious and depressive symptoms, appetite and sleep pattern. ${ }^{32}$

With regard to anxiety symptoms, Asmundson and Katz ${ }^{33}$ reported that pain-related anxiety can justify treatment specifically for anxiety, as this condition is a potential vulnerability and can increase sensitivity to disease and fear of pain, making it difficult the effectiveness of the treatment. Bair et al. ${ }^{34}$ found that pain, when associated with anxiety and depression, is more disabling, and implies a worse quality of life in relation to patients who present only pain.

The damages most involved in chronic pain are medium term, which include problems with sleep, work absenteeism, relationship problems and increased risk of accidents; and long-term that are characterized by the consequences of sleep disorders with loss of employment, sequelae resulting from accidents, breakdown of relationships, appearance or aggravation of health problems. These factors invariably significantly affect the quality of life of the subject with chronic pain. ${ }^{35}$

The main limitation of this study is related to the temporality of the diagnosis and therapeutic approach, which was carried out by several professionals, from different specialties; in addition to the sample characteristic, heterogeneity of pain etiology and sociodemographic data, which did not allow analyzing all variables included in the study. On the other hand, the fact that it was performed at a referral center can be a positive predictive factor, as it minimizes an eventual bias of diagnostic error and therapeutic approach of the studied pathologies.

As recommendations for future research, follow-up studies are indicated aiming at monitoring the response to the indicated treatment and its effective results in the intensity of pain and in the response of the individual's quality of life scores, as well as an active and careful listening by the health team to in order to understand and value the symptoms of the individual suffering from pain, which goes far beyond a complaint, but above all in understanding their history and the suffering inherent to their illness process. 


\section{Conclusion}

People who have chronic pain, have low scores on items related to quality of life in the presence of anxious and depressive symptoms and many limitations in daily activities; especially those related to work, leisure and home activities, showing an important impairment in sleep patterns, sexual activity and appetite.

\section{Acknowledgments}

None.

\section{Conflicts of interest}

No financial, legal or political conflicts involving third parties (government, companies and private foundations, etc.); was declared for any aspect of the submitted work (including, but not limited to grants and funding, advisory board, study design, manuscript preparation, statistical analysis, etc.

\section{References}

1. Luiz Fernando R, Lidiane IF. Prevalence of chronic pain in a Basic Health Unit of a middle-sized city. Rev Dor. 2012;13(2):128-131.

2. Juan Pablo MM, David EAR. Medicina Legal de Costa Rica. Rev Med Leg. 2016;33(1):219-227.

3. Turner-Stokes L, Goebel A; Guideline Development Group. Complex regional pain syndrome in adults: concise guidance. Clin Med (Lond). 2011;11(6):596-600.

4. Sakata R. Nomenclatura e Classificação da Dor. Guias de Medicina Ambulatorial e Hospitalar/Unifesp-Dor. 2008;2.

5. Cipriano A, Almeida DB, Vall J. Profile of chronic pain patients seen in a pain outpatient setting of a major Southern Brazil' city. Rev Dor. 2011;12(4):297-300.

6. Breuer B, Cruciani R, Portenoy RK. Pain Management by Primary Care Physicians, Pain Physicians, Chiropractors, and Acupuncturists: A National Survey. South Med J. 2010;103(8):738-747.

7. Turk DC, Wilson HD. Fear of pain as a prognostic factor in chronic pain: conceptual models, assessment, and treatment implications. Current pain and headache reports, 2010;14(2):88-95.

8. Vasconcelos FH, Araújo GC de. Prevalence of chronic pain in Brazil: a descriptive study. BrJP. 2018;1(2):176-179.

9. Baliki MN, Schnitzer TZ, Bauer WR, et al. Brain Morphological Signatures for chronic pain. PloSONe. 2011;6(10):1-13.

10. Apkarian AV, Baliki MN, Geha PY. Towards a theory of chronic pain. Prog Neurobiol. 2009;87(2):81-97.

11. IASP Task Force on Taxonomy. Part III: Pain terms, a current list with definitions and notes on usage. Classification of chronic pain. 1994. 209-214.

12. Onofre AN. Dor: princípios e prática. Artmed Editora. 2009.

13. Neubern MS. Psychotherapy, Pain and Complexity: Building the Therapeutic Context. Psicologia: Teoria e Pesquisa. 2010;3(26):515523.

14. Sallum AMC, Garcia DM, Sanches M. Acute and chronic pain: a narrative review of the literature. Acta Paulista de Enfermagem. 2012;25(1)

15. Noble Bill, Clark D, Meldrum M, et al. The measurement of pain, 19452000. Journal of pain and symptom management. 2005;29(1):14-21.

16. Botega NJ, Pondé MP, Medeiros P, Lima MG, Guerreiro CAM.et al. Validity of the Hospital Anxiety and Depression Scale in Patients with Chronic Pain. Jornal Brasileiro de Psiquiatria. 1998;47:285-289.
17. Ciconelli RM. Validation of the brazilian version of the generic sixdimensional short form quality of life questionnaire (SF-6D Brazil). Escola Paulista de Medicina, São Paulo, 1997.

18. Kreling MCGD, da Cruz DALM, Pimenta CA de M. Prevalence of chronic pain in adult workers. Rev Bras Enferm. 2006;59(4):509-513.

19. Sá K, Baptista AF, Matos MA, Lessa I. Prevalence of chronic pain and associated factors in the population of Salvador, Bahia. Rev Saude Publica. 2009;43(4):622-630.

20. Alessandro Ribeiro de Pádua, Oliveira IM, Alves AP, et al. Analysis of the relationship between $\mathrm{M}$ wave parameters and pain. Rev Dor. 2011;12(4):301-307.

21. Theadom A, Cropley M, Humphrey KL. Exploring the role of sleep and coping in quality of life in fibromyalgia. $J$ Psychosom Res. 2007;62(2):145-151.

22. Latina R, De Marinis MG, Giordano F, et al. Epidemiology of Chronic Pain in the Latium Region, Italy: A Cross-Sectional Study on the Clinical Characteristics of Patients Attending Pain Clinics. Pain Manag Nurs. 2019;(17):S1524-9042.

23. Pinheiro RC, Uchida RR, Mathias LA da ST, et al Prevalence of depressive and anxiety symptoms in patients with chronic pain. $J$ Bras Psiquiatr. 2014;63(3):213-219.

24. Camilla DDRL, Manoel JT, Silvia RDTDS. Spirituality and religiosity in combating pain. 2010;34(4):483-487.

25. Hasegawa T, Katsuhira J, Oka H, et al. Association of low back load with low back pain during static standing. PLoS One. 2018;13(12):e0208877.

26. Perolat R, Kastler A, Nicot B, et al. Facet joint syndrome: from diagnosis to interventional management. Insights Imaging. 2018;9(5):773-789.

27. Laursen M, Nielsen CV, Jørgensen LB, Andersen NT. A web-based platform to accommodate symptoms of anxiety and depression by featuring social interaction and animated information in patients undergoing lumbar spine fusion: a randomized clinical trial. Spine $J$. 2019;19(5):827-839.

28. Terrier P, Praz C, Joane Le Carré J, et al. Influencing walking behavior can increase the physical activity of patients with chronic pain hospitalized for multidisciplinary rehabilitation: an observational study. BMC Musculoskeletal Disorders. 2019;20:188.

29. Pagé MG, Ziemianski D, Martel MO, et al. Development and validation of the Treatment Expectations in Chronic Pain Scale. British Journal of Health Psychology 2019;24(3):610-628.

30. Laguardia J, Campos M R, Travassos C, et al. Brazilian normative data for the Short Form 36 questionnaire, version 2. Rev Bras Epidemiol. 2013;16(4):889-897.

31. Tsuji T, Matsudaira K, Sato H1, et al. Association between presenteeism and health-related quality of life among Japanese adults with chronic lower back pain: a retrospective observational study. BMJ Open. 2018 27;8(6):e021160

32. Bailly F, Foltz V, Rozenberg S, et al. The impact of chronic low back pain is partly related to loss of social role: A qualitative study. Joint Bone Spine. 2015;82(6):437-441.

33. Asmundson GJG, Katz J. Understanding the co-occurrence of anxiety disorders and chronic pain: State-of-the-art. Depress Anxiety. 2009;26(10):888-901.

34. Bair MJ, Wu J, Damush TM, et al. Association of depression and anxiety alone and in combination with chronic musculoskeletal pain in primary care patients. Psychosom Med. 2008;70(8):890-897.

35. Müller MR, Guimarães SS. Sleep disorders impact on daily functioning and life quality. Estud Psicol. 2007;24(4):519-28. 